\title{
Anisotropy of acousto-optic figure of merit in tetragonal crystals with accounting for non-orthogonality of acoustic eigenwave polarizations. \\ 2. The cases of $\mathrm{Li}_{2} \mathrm{~B}_{4} \mathrm{O}_{7}$ and $\mathrm{TeO}_{2}$ crystals
}

\author{
Mys O., Savaryn V., Kostyrko M., Adamenko D., Krupych O. and Vlokh R. \\ Vlokh Institute of Physical Optics, 23 Dragomanov Street, 79005 Lviv, Ukraine, \\ vlokh@ifo.lviv.ua
}

Received: 05.02.2019

\begin{abstract}
We analyze anisotropy of acousto-optic figure of merit (AOFM) $M_{2}$ at the isotropic acousto-optic (AO) diffraction in $\mathrm{Li}_{2} \mathrm{~B}_{4} \mathrm{O}_{7}$ and $\mathrm{TeO}_{2}$ crystals. The diffraction takes place inside crystallographic planes, under the condition that the effect of non-orthogonality of acoustic-wave polarizations is taken into account. The geometries of $\mathrm{AO}$ diffraction, at which maximal AOFM values are reached, are determined for all the types of isotropic $\mathrm{AO}$ interactions. It is found that the global AOFM maximum for $\mathrm{Li}_{2} \mathrm{~B}_{4} \mathrm{O}_{7}$ in the case of isotropic diffraction is equal to $M_{2}=3.4 \times 10^{-15} \mathrm{~s}^{3} / \mathrm{kg}$. It is achieved using the type $I$ of AO interactions with a socalled acoustic wave $\mathrm{QT}_{1}$ in the crystallographic planes $a c$ or $b c$. For $\mathrm{TeO}_{2}$ crystals, the AOFM maximum for the isotropic AO interactions $\left(M_{2}=71.0 \times 10^{-15} \mathrm{~s}^{3} / \mathrm{kg}\right)$ is achieved at the type $I V$ of $\mathrm{AO}$ interactions in the principal planes $a c$ or $b c$.
\end{abstract}

Keywords: acousto-optic figure of merit, anisotropy, tetragonal crystals, $\mathrm{Li}_{2} \mathrm{~B}_{4} \mathrm{O}_{7}$, $\mathrm{TeO}_{2}$, non-orthogonality of acoustic wave polarization

PACS: $78.20 . \mathrm{Hp}, 42.79 . \mathrm{Jq}$

UDC: $535.42,535.012 .2$

\section{Introduction}

The acousto-optic figure of merit (AOFM) is determined by the relationship $M_{2}=n^{6} p_{e f}^{2} / \rho v^{3}$, where $\rho$ denotes the material density, $n$ the refractive index, $p_{e f}$ the effective elasto-optic coefficient (EEC), and $v$ the velocity of the acoustic wave (AW). In the first part of the present work [1], we have derived the EEC with accounting for AW polarization non-orthogonality for the crystals belonging to the symmetry groups $\overline{4} 2 \mathrm{~m}, 4 / \mathrm{mmm}, 422$ and $4 \mathrm{~mm}$. Here the nonorthogonality effect implies inclinations of the displacement vectors of acoustic eigenmodes relative to the ultrasound wave vector, which manifests itself in a non-parallelism of the longitudinal wave and a non-orthogonality of one (or both) shear AWs relative to the wave vector. In the mentioned work, the AOFM anisotropies have been examined under conditions when the $\mathrm{AW}$ non-orthogonality effect is either neglected or taken into account. Particular cases of $\mathrm{KH}_{2} \mathrm{PO}_{4}$ (KDP) and $\mathrm{NH}_{4} \mathrm{H}_{2} \mathrm{PO}_{4}$ (ADP) crystals have been analyzed for the interactions occurring in the crystallographic planes. It has been found that proper consideration of the angle of AW nonorthogonality can change significantly the AOFM values. The acousto-optic (AO) diffraction geometries corresponding to AOFM maximums have been obtained for all of the nine types of AO interactions, including those concerned with the collinear diffraction.

A great number of efficient $\mathrm{AO}$ materials belong to the crystals of tetragonal system. One of these materials is paratellurite, $\mathrm{TeO}_{2}$, which belongs to the point symmetry group 422 [2]. 
Paratellurite is characterized by the AOFM as high as $1200 \times 10^{-15} \mathrm{~s}^{3} / \mathrm{kg}$ [3]. The other crystal that represents tetragonal $\mathrm{AO}$ materials and belongs to the point group $4 \mathrm{~mm}$ is lithium tetraborate, $\mathrm{Li}_{2} \mathrm{~B}_{4} \mathrm{O}_{7}$. It is highly resistant to a high-power optical radiation, with the damage threshold being equal to $40 \mathrm{GW} / \mathrm{cm}^{2}[4,5]$. The crystal is transparent in the UV spectral range down to $170 \mathrm{~nm}$ [5] and represents a promising AO material [6-9] for operating high-power short-wavelength optical radiation. As shown in our recent work [9], the maximal AOFM for the $\mathrm{Li}_{2} \mathrm{~B}_{4} \mathrm{O}_{7}$ crystals can reach the value $3.44 \times 10^{-15} \mathrm{~s}^{3} / \mathrm{kg}$ in the visible spectral range. The maximum AOFM for the paratellurite crystals is equal to $1143.8 \times 10^{-15} \mathrm{~s}^{3} / \mathrm{kg}$ for the isotropic diffraction [10] and $750 \times 10^{-15} \mathrm{~s}^{3} / \mathrm{kg}$ for the anisotropic AO interactions that involve linearly polarized optical waves [11]. However, these values have been obtained with no accounting for the deviations of AW polarizations from the purely transverse or longitudinal states.

It is also important that an analytical method for the studies of AOFM anisotropy have already been developed for the interaction planes coinciding with the principal crystallographic planes. It is worthwhile that this method accounts for the effect of non-orthogonality of the AWs [12]. As shown in Ref. [12], consideration of the deviations of AW polarizations from the purely longitudinal or transverse states changes essentially the relations for the EEC. As a result, this affects heavily the final AOFM values. The aim of the second part of our work is to analyze the AOFM anisotropy in the tetragonal crystals $\mathrm{TeO}_{2}$ and $\mathrm{Li}_{2} \mathrm{~B}_{4} \mathrm{O}_{7}$ under the condition of taking the AW non-orthogonality into account.

\section{Acoustic and optical properties of $\mathrm{Li}_{2} \mathrm{~B}_{4} \mathrm{O}_{7}$ and $\mathrm{TeO}_{2}$ crystals}

We recite the main properties of $\mathrm{Li}_{2} \mathrm{~B}_{4} \mathrm{O}_{7}$ and $\mathrm{TeO}_{2}$ needed for our further analysis. These crystals are optically uniaxial at the room temperature. At the light wavelength $\lambda=632.8 \mathrm{~nm}$, the refractive indices for $\mathrm{Li}_{2} \mathrm{~B}_{4} \mathrm{O}_{7}$ are equal to $n_{o}=1.6088$ and $n_{e}=1.5520$, so that the crystal is optically negative [13]. For the optically positive $\mathrm{TeO}_{2}$ crystal we have $n_{o}=2.2597$ and $n_{e}=2.4119$ [14]. The densities of $\mathrm{Li}_{2} \mathrm{~B}_{4} \mathrm{O}_{7}$ and $\mathrm{TeO}_{2}$ are equal to $\rho=2440 \mathrm{~kg} / \mathrm{m}^{3}$ and $\rho=5990 \mathrm{~kg} / \mathrm{m}^{3}$, respectively $[15,16]$. In our calculations, we have used the known elastic-stiffness $\left(C_{11}=135.27 \pm 0.12, C_{12}=1.09 \pm 0.06, C_{13}=31.86 \pm 0.10, C_{33}=54.80 \pm 0.10, C_{44}=57.39 \pm 0.08\right.$ and $\left.C_{66}=47.38 \pm 0.06 \mathrm{GPa} \quad[13]\right) \quad$ and elasto-optic $\left(p_{11}=0.083 \pm 0.003, \quad p_{12}=0.227 \pm 0.017\right.$, $p_{13}=0.227 \pm 0.005, \quad p_{31}=0.209 \pm 0.011, \quad p_{33}=0.163 \pm 0.006, \quad p_{44}=-0.0075 \pm 0.0061 \quad$ and $p_{66}=-0.066 \pm 0.002$ [17]) coefficients of the $\mathrm{Li}_{2} \mathrm{~B}_{4} \mathrm{O}_{7}$ crystals. In the case of $\mathrm{TeO}_{2}$ crystals, the elastic stiffness coefficients are equal to $C_{11}=53.2, C_{12}=48.6, C_{13}=21.2, C_{33}=108.5, C_{44}=24.4$ and $C_{66}=55.2 \mathrm{GPa}$, while the elasto-optic coefficients amount to $p_{11}=0.0074, p_{12}=0.187$, $p_{13}=0.34, p_{31}=0.0905, p_{33}=0.24, p_{44}=-0.17$ and $p_{66}=-0.0463$ [16].

The anisotropy of AW velocities in crystals can be analyzed using the Christoffel equation [18]:

$$
C_{i j k l} m_{j} m_{k} p_{l}=\rho v^{2} p_{i},
$$

where $C_{i j k l}$ denote the components of elastic-stiffness tensor, $m_{j}$ and $m_{k}$ the components of the unit $\mathrm{AW}$ vector, and $p_{i}$ and $p_{l}$ the components of the unit displacement vector. For the tetragonal crystals of the symmetry groups $\overline{4} 2 \mathrm{~m}, 4 / \mathrm{mmm}, 422$ and $4 \mathrm{~mm}$, the angle of deviation of the acoustic polarization from the purely longitudinal type is calculated following from the Christoffel equation [18]:

$$
\Delta=\zeta-\theta=\frac{1}{2} \arctan \frac{\left(C_{13}+C_{44}\right) \sin 2 \theta}{\left(C_{11}-C_{44}\right) \cos ^{2} \theta+\left(C_{44}-C_{33}\right) \sin ^{2} \theta}-\theta,
$$




$$
\Delta=\zeta-\theta=\frac{1}{2} \arctan \left(\frac{C_{12}+C_{66}}{C_{11}-C_{66}} \tan 2 \theta\right)-\theta
$$

Eqs. (2) and (3) concern respectively the $a c$ (or $b c$ ) and $a b$ planes, $\theta$ implies the angle between the AW vector and the $a$ (or $b$ ) axis, and $\zeta$ the angle between the same axis and the displacement vector. Since the polarizations of the acoustic eigenmodes are mutually orthogonal, the corresponding non-orthogonality of the quasi-transverse (QT) waves can, in principle, be calculated with the same formulae. The only difference is that an additive term $90 \mathrm{deg}$ should be added to the r.-h. s. of Eqs. (2) and (3). As seen from Fig. 1, the angle of non-orthogonality for the $\mathrm{Li}_{2} \mathrm{~B}_{4} \mathrm{O}_{7}$ crystals reaches $-25.8 \mathrm{deg}$ in the $a c$ plane and $\pm 8.4 \mathrm{deg}$ in the $a b$ plane. For the $\mathrm{TeO}_{2}$ crystals this angle reaches the value $-15.8 \mathrm{deg}$ in the $a c(b c)$ plane and $\pm 37.1 \mathrm{deg}$ in the $a b$ plane.

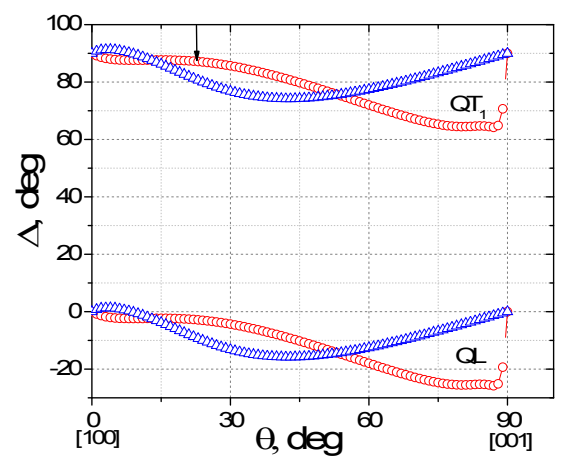

(a)

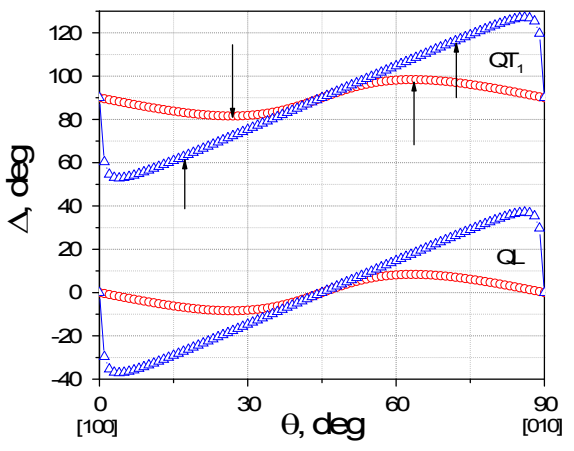

(b)

Fig. 1. Dependences of non-orthogonality angle on the $\mathrm{AW}$ vector orientation for $\mathrm{Li}_{2} \mathrm{~B}_{4} \mathrm{O}_{7}$ (circles) and $\mathrm{TeO}_{2}$ (triangles) crystals in the crystallographic planes $a c$ (a) and $a b$ (b). QL implies quasi-longitudinal wave. The angular positions at which polarization of $\mathrm{QT}_{1} \mathrm{AW}$ are switched on 90 deg are indicated by arrows.
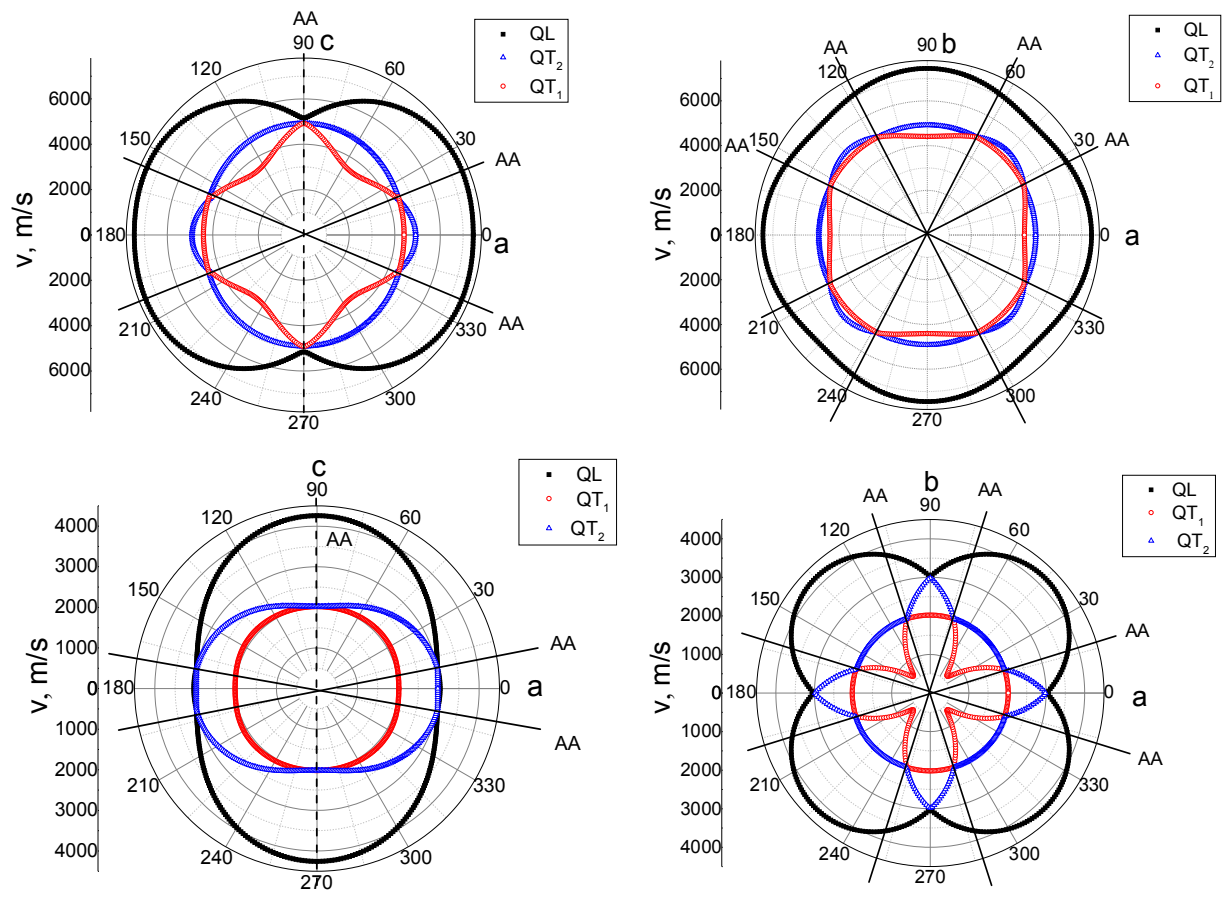

Fig. 2. Cross sections of $A W$ velocity surfaces by the principal crystallographic planes for $\mathrm{Li}_{2} \mathrm{~B}_{4} \mathrm{O}_{7}$ (a) and $T e \mathrm{O}_{2}$ (b): AA denote the acoustic axes. 


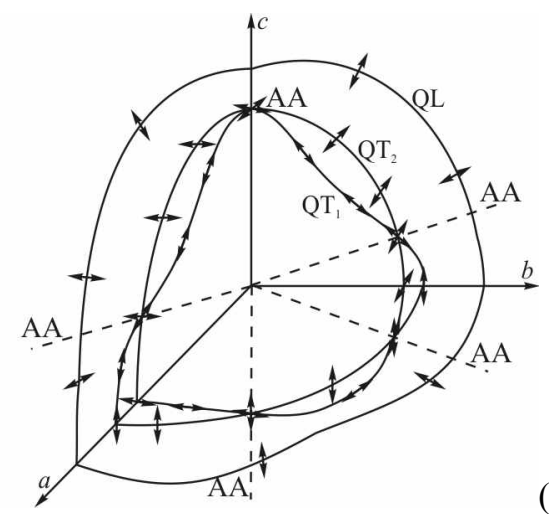

(a)

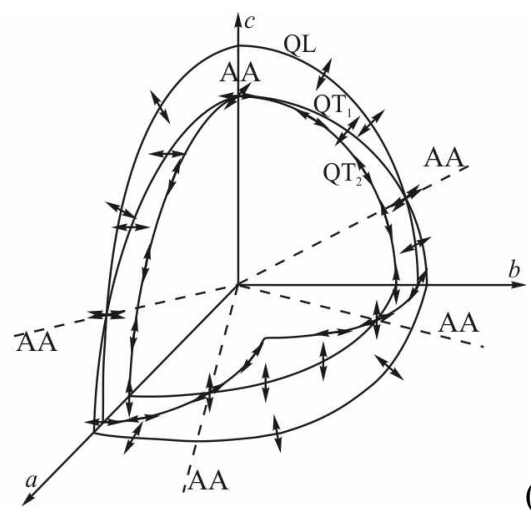

(b)

Fig. 3. Schematic view of parts of the $A W$ velocity surfaces for $\mathrm{Li}_{2} \mathrm{~B}_{4} \mathrm{O}_{7}(\mathrm{a})$ and $\mathrm{TeO}_{2}$ (b).

The cross sections of the AW velocity surfaces are also similar for the $\mathrm{Li}_{2} \mathrm{~B}_{4} \mathrm{O}_{7}$ and $\mathrm{TeO}_{2}$ crystals (Fig.2). A schematic view of parts of the AW velocity surfaces, which are common for the both crystals, is presented in Fig. 3. There are nine acoustic axes in the $\mathrm{Li}_{2} \mathrm{~B}_{4} \mathrm{O}_{7}$ crystals, which represent those propagation directions where the AWs QT have the same phase velocity. One of the acoustic axis is parallel to the crystallographic axis $c$, four of these axes lie in the $a b$ plane, and two of them belong to the $a c$ and $b c$ planes. The angular dependences of the AW velocities for the two AWs QT in $\mathrm{Li}_{2} \mathrm{~B}_{4} \mathrm{O}_{7}$ and $\mathrm{TeO}_{2}$ touch each other in the principal planes. For the $\mathrm{Li}_{2} \mathrm{~B}_{4} \mathrm{O}_{7}$ crystals, the points where these surfaces are touched lie at the angles 22 and 202 deg or 158 and 338 deg with respect to the $a(b)$ axis in the $a c(b c)$ plane (see Fig. 2 and Fig. 3). The outlets of the acoustic axes in the $a b$ plane lie at the angles 27 and $207 \mathrm{deg}, 63$ and $243 \mathrm{deg}, 117$ and $297 \mathrm{deg}$, and 163 and $333 \mathrm{deg}$ with respect to the $a$ axis. The difference between the velocities of AWs QL and QT propagating along the $c$ axis is equal to $244.6 \mathrm{~m} / \mathrm{s}$.

$\mathrm{TeO}_{2}$ has five acoustic axes. When the AWs propagate along these axes, the velocity of the two QT waves are equal to each other. When the AWs propagate along the other two acoustic axes, the velocity of the QL wave is equal to the velocity of $\mathrm{QT}_{2}$ wave (see Fig. 2b). For the $\mathrm{TeO}_{2}$ crystals, the angles between the acoustic axes and the $a$ axis in the $a b$ plane are equal to 17.0 and $197.0 \mathrm{deg}, 73$ and $253 \mathrm{deg}, 117$ and $287 \mathrm{deg}$, and 163 and $343 \mathrm{deg}$. One of the acoustic axes is parallel to the $c$ axis. In fact, the points mentioned above are nothing but polarization singularities, or topological defects of polarization orientation, with their strength equal to $1 / 2$. This means that the AW polarization in the $a b$ plane within the same AW velocity surface is switched by $90 \mathrm{deg}$ when the wave vector crosses the acoustic-axis direction. The acoustic axis parallel to the $c$ axis also represents the polarization singularity. However, the strength of this topological defect of polarization distribution is equal to unity. Two so-called transverse-longitudinal acoustic axes exist in the $a c(b c)$ plane. They lie at the angles 9 and $189 \mathrm{deg}$ (or 171 and $351 \mathrm{deg}$ ) with respect to the $a(b)$ axis.

The relations for the EEC have been presented in the first part of the present work [1]. Since they contain some errors, we report the correct relations in the Appendix. They also have to be used with accounting for the polarization switching for the AWs QT occurring after crossing, by the wave vector, of the outlets of the acoustic axes in crystals. In our calculations, we have taken the Bragg angle to be equal to $1 \mathrm{deg}$. Note that accounting for the AW polarization nonorthogonality does not affect the relation for the EEC in the principal crystallographic planes, whenever the tetragonal symmetry groups and the case of anisotropic diffraction are considered. This type of diffraction in $\mathrm{Li}_{2} \mathrm{~B}_{4} \mathrm{O}_{7}$ and $\mathrm{TeO}_{2}$ has been analyzed in the recent works [9, 11], and the 
non-orthogonality effect has been properly considered. Therefore, in the present paper we will deal only with the isotropic type of $\mathrm{AO}$ diffraction.

\section{Results and discussion}

\section{1. $\mathrm{Li}_{2} \mathrm{~B}_{4} \mathrm{O}_{7}$ crystals}

The AOFM anisotropy for the types $I$ and $I I$ of AO interactions in $\mathrm{Li}_{2} \mathrm{~B}_{4} \mathrm{O}_{7}$ is illustrated in Fig. 4. The type $I$ of interactions concerns isotropic diffraction of the ordinary optical wave at the grating caused by the AW QL. The type II deals with AO interactions of the extraordinary optical wave with the same grating. As seen from Fig. 4a and Fig. 4b, consideration of the non-orthogonality in case of the type $I$ of AO interactions does not affect essentially the AOFM in the $a b$ plane. Splitting of the AOFM dependences calculated under alternative conditions of accounting for or neglecting by the AW non-orthogonality in the $a c(b c)$ plane is observed in the angular regions $45<\theta<135 \mathrm{deg}$ and $225<\theta<315 \mathrm{deg}$. As seen from Fig. 1a, polarization deviation from the purely longitudinal type increases in these regions. At the same time, the deviation angle in the $a b$ plane remains small enough (see Fig. 1b). The maximal AOFM value, $3.4 \times 10^{-15} \mathrm{~s}^{3} / \mathrm{kg}$, for the type $I$ of interactions is reached in the $a c(b c)$ plane when the AW propagates along the $c$ axis.
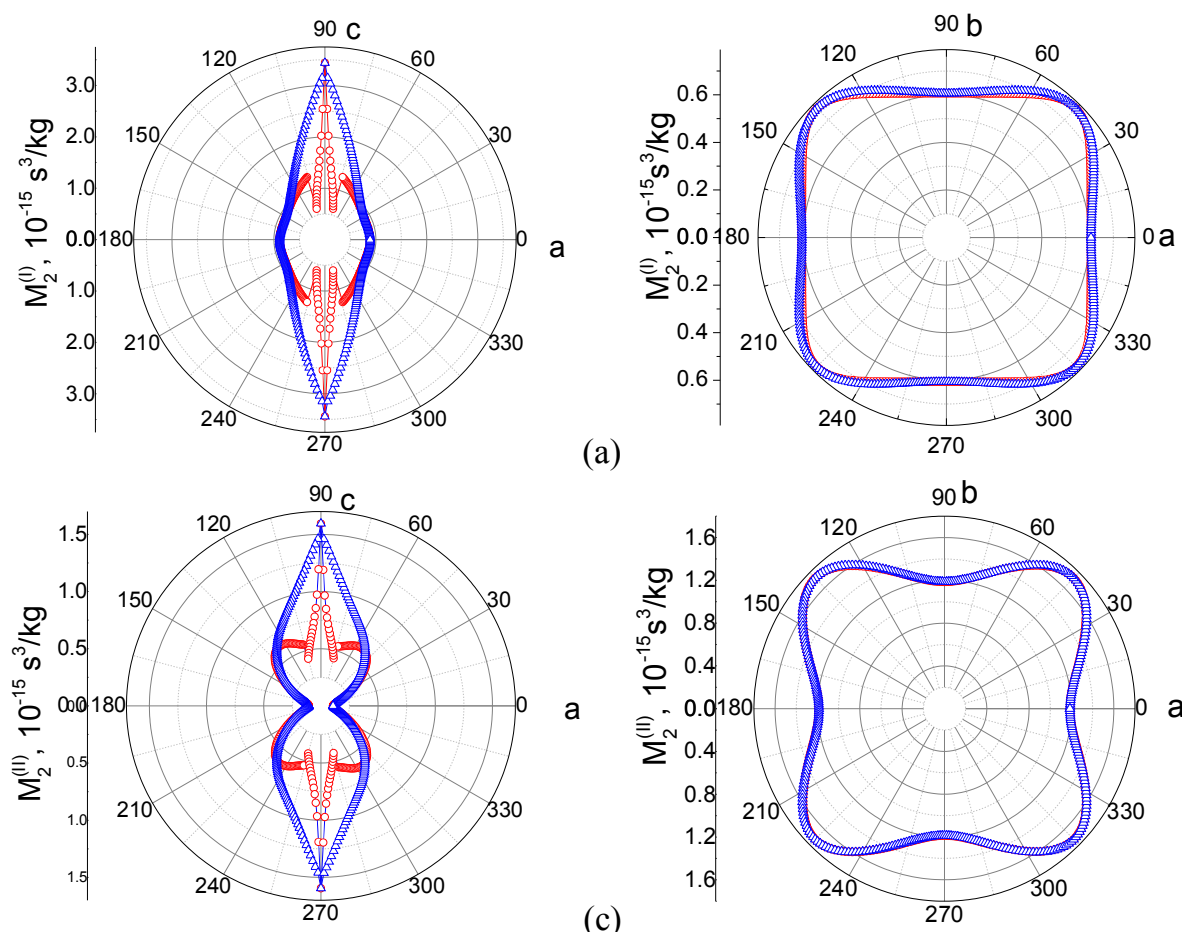

(a)

(c)

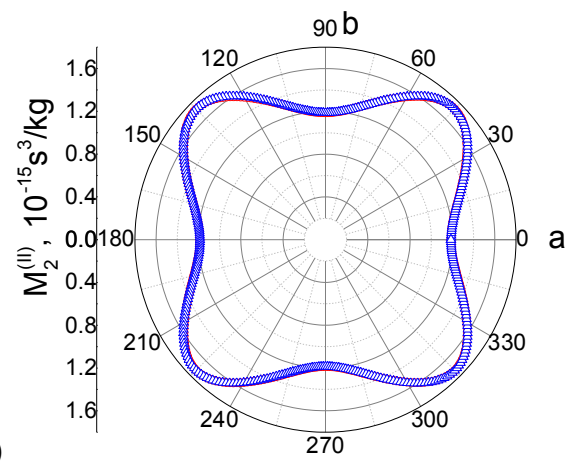

(d)

Fig. 4. Dependences of AOFM on the angle $\theta$ for the types $I(a, b)$ and $I /(c, d)$ of $A O$ interactions in the $a c(b c)$ (a, c) and $a b$ (b, d) planes for the $\mathrm{Li}_{2} \mathrm{~B}_{4} \mathrm{O}_{7}$ crystals: open triangles and circles correspond respectively to neglecting and taking the AW non-orthogonality into account.

A similar behaviour of AOFM is observed for the type II of AO interactions (see Fig. 4c, d). Namely, accounting for the deviation of AW polarizations from the pure types does not affect the AOFM for the $a b$ plane, though it influences this parameter in case of the $a c(b c)$ interaction plane and the angles $45<\theta<135 \mathrm{deg}$ and $225<\theta<315 \mathrm{deg}$. The maximal AOFM value for the type II of interactions, $1.7 \times 10^{-15} \mathrm{~s}^{3} / \mathrm{kg}$, is achieved in the $a b$ plane when the AW propagates at the angles 45 , 135,225 and $315 \mathrm{deg}$ with respect to the $a$ axis.

Ukr. J. Phys. Opt. 2019, Volume 20, Issue 1 


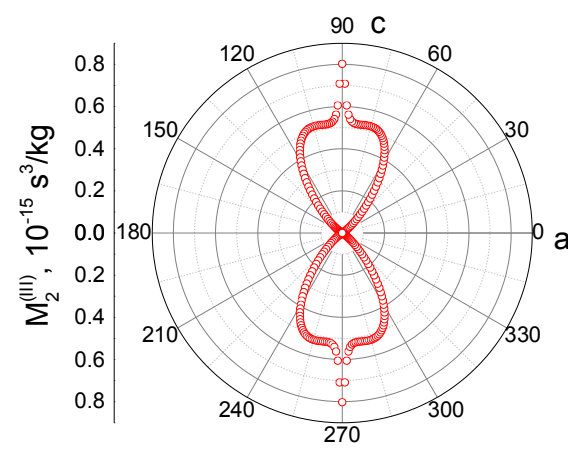

(a)
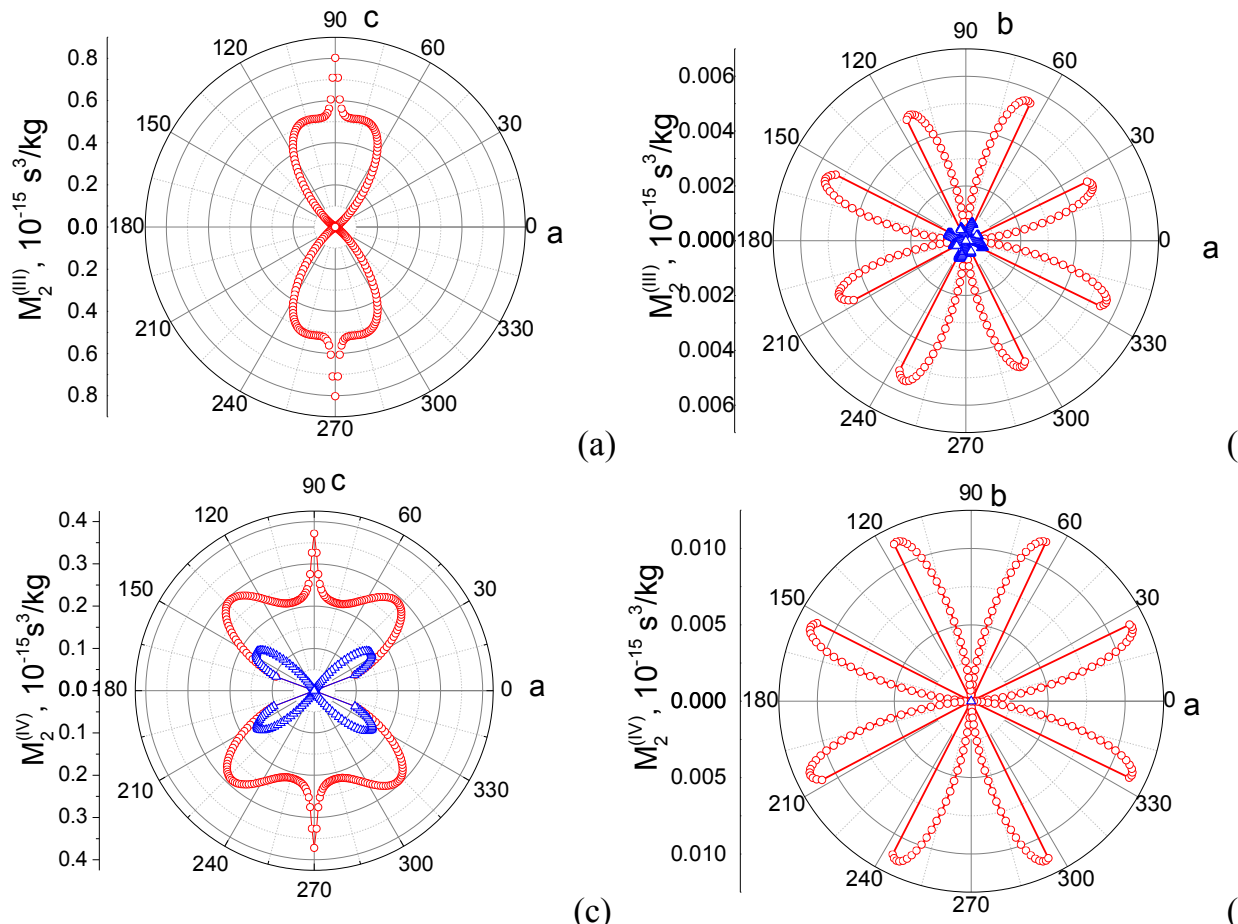

Fig. 5. Dependences of AOFM on the angle $\theta$ for the types $I I I(a, b)$ and $I V(c, d)$ of $A O$ interactions in the ac $(b c)(a, c)$ and $a b(b, d)$ planes for the $\mathrm{Li}_{2} \mathrm{~B}_{4} \mathrm{O}_{7}$ crystals: open triangles and circles correspond respectively to neglecting and taking the AW non-orthogonality into account.

The type III implies AO interactions of the ordinary optical wave with the $\mathrm{AW}_{\mathrm{QT}}$. Let the AW be polarized perpendicular to the $a c(b c)$ plane at the angles $338<\theta<22 \mathrm{deg}$ and $158<\theta<202 \mathrm{deg}$, and the AW polarization vector lie in the the $a c(b c)$ plane at the angles $22<\theta<158 \mathrm{deg}$ and $202<\theta<338 \mathrm{deg}$. Then the above interactions seem to be impossible till the AW non-orthogonality is accounted for. Indeed, when the non-orthogonality is neglected, the EEC is written as

$$
p_{e f}^{(I I I)}=\left(p_{12}-p_{13}\right) \sin 2 \theta .
$$

Since we have the equality $p_{12} \approx p_{13}$ for the mean values of elastooptic coefficients of $\mathrm{Li}_{2} \mathrm{~B}_{4} \mathrm{O}_{7}$, this leads to the condition $p_{e f}^{(I I I)} \approx 0$. In other words, the AOFM is zero for the $a c(b c)$ plane when we deal with the type $I I I$ of interactions and the non-orthogonality is neglected (see Fig. 5a). However, the AO diffraction can still be implemented in the $a c(b c)$ plane after the AW polarization non-orthogonality is considered properly. Then the AOFM maximum, $0.8 \times 10^{-15} \mathrm{~s}^{3} / \mathrm{kg}$, is reached at $\theta=90$ and $270 \mathrm{deg}$. In the $a b$ plane, the type $I I I$ of $\mathrm{AO}$ interactions cannot be realized at the angles of AW propagation equal $27<\theta<63 \mathrm{deg}, 117<\theta<163 \mathrm{deg}, 207<\theta<243 \mathrm{deg}$ and $297<\theta<333 \mathrm{deg}$, since the appropriate elstooptic coefficients are zero (see Fig. 5b). At the other angles of AW vector orientation, the AOFM under the condition of neglected nonorthogonality is smaller than that calculated when the effect is taken into account. The maximal AOFM value, $0.005 \times 10^{-15} \mathrm{~s}^{3} / \mathrm{kg}$, is reached in the $a b$ plane at the angles of AW propagation equal to $\theta=24,66,114,156,204,246,294$ and $336 \mathrm{deg}$.

The type $I V$ of interactions concerns diffraction of the extraordinary optical wave at the AO

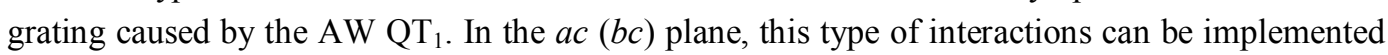


only when the AW propagates at the angles $21<\theta<160$ deg and $200<\theta<339$ deg. Accounting for deviations from the $\mathrm{AW}$ orthogonality leads to increasing AOFM (see Fig. $5 \mathrm{c}$ ). The maximum AOFM, $0.4 \times 10^{-15} \mathrm{~s}^{3} / \mathrm{kg}$, is achieved at the angles of AW vector orientation $\theta=90$ and $270 \mathrm{deg}$ in the $a c(b c)$ plane. The AO interactions in the $a b$ plane are impossible under condition of purely transverse AWs. However, when we account for the real deviations of AW polarizations from the purely transverse states, it turns out that the $\mathrm{AO}$ interactions can exist at the AW propagation angles $333<\theta<27 \mathrm{deg}, 117<\theta<63 \mathrm{deg}, 153<\theta<207 \mathrm{deg}$ and $243<\theta<297 \mathrm{deg}$ (see Fig. $5 \mathrm{~d}$ ). The maximal AOFM is equal to $0.01 \times 10^{-15} \mathrm{~s}^{3} / \mathrm{kg}$ at the angles $\theta=25,65,115,155,205,245,295$ and $335 \mathrm{deg}$.

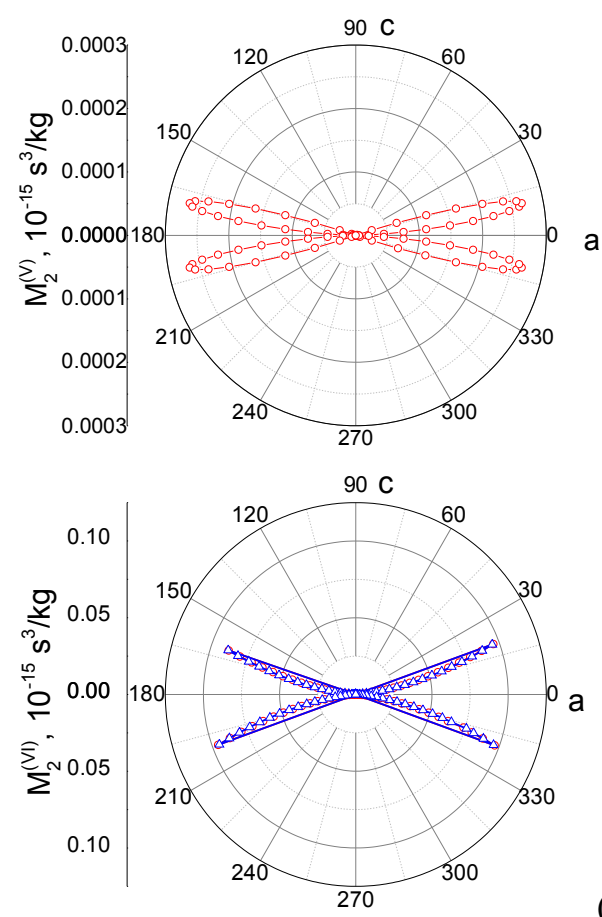

(a)

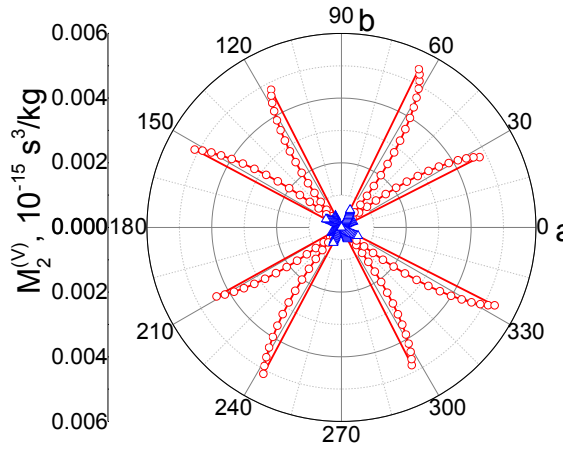

(b)

(c)

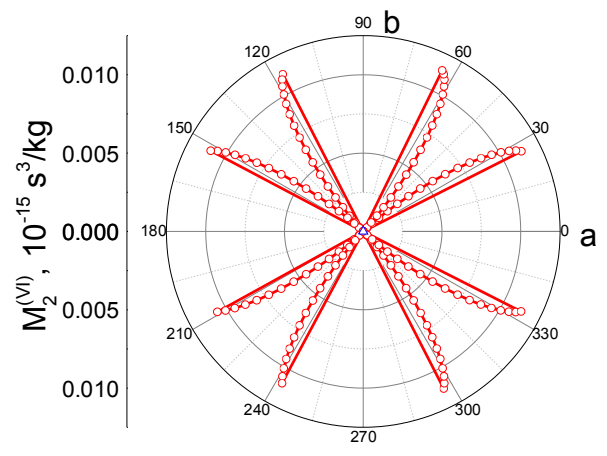

(d)

Fig. 6. Dependences of AOFM on the angle $\theta$ for the types $V(a, b)$ and $V I(c, d)$ of $A O$ interactions in the ac $(b c)(a, c)$ and $a b(b, d)$ planes for the $\mathrm{Li}_{2} \mathrm{~B}_{4} \mathrm{O}_{7}$ crystals: open triangles and circles correspond respectively to neglecting and taking the AW non-orthogonality into account.

For the type $V$ of $\mathrm{AO}$ interactions of the ordinary optical wave with the $\mathrm{AW}_{2} \mathrm{QT}_{2}$ in the $a c$ (bc) plane, the $\mathrm{EEC}$ of $\mathrm{Li}_{2} \mathrm{~B}_{4} \mathrm{O}_{7}$ is equal to zero as long as the $\mathrm{AW}$ non-orthogonality is neglected. Hence, this type of interactions in the $a c(b c)$ plane is impossible as long as the non-orthogonality is neglected (see Fig. 6a). The same concerns the type VI of interactions of the extraordinary optical wave with the $\mathrm{AW} \mathrm{QT}_{2}$ in the $a b$ plane (see Fig. 6d). With taking the non-orthogonality effect into account for the $a c(b c)$ plane, the type $V$ of interactions can be implemented in the region of AW vector orientations given by $339<\theta<21 \mathrm{deg}$ and $159<\theta<181 \mathrm{deg}$. The maximal AOFM, $0.001 \times 10^{-15} \mathrm{~s}^{3} / \mathrm{kg}$, is reached at $\theta=11,169,191$ and $349 \mathrm{deg}$. The types $V$ and $V I$ of interactions in the $a b$ plane can be implemented in the angular regions $27<\theta<63 \mathrm{deg}$, $117<\theta<163 \mathrm{deg}, 207<\theta<243 \mathrm{deg}$ and $297<\theta<333 \mathrm{deg}$ (see Fig. 6b, d).

The type $V I$ of interactions is impossible (see Fig. 6d) when the non-orthogonality effect is neglected, since the relevant EEC is zero. However, the type $V$ of AO interactions can be realized under these conditions (see Fig. 6b). In the latter case, the maximal AOFM is smaller than that observed under the condition when the AW non-orthogonality is accounted for in case of the AW 
$\mathrm{QT}_{2}$. The AOFM maximum, $0.006 \times 10^{-15} \mathrm{~s}^{3} / \mathrm{kg}$, for the type $V$ of interactions is reached in the $a b$ plane at the angles $\theta=64,152,242$ and $333 \mathrm{deg}$. The AOFM maximum $0.01 \times 10^{-15} \mathrm{~s}^{3} / \mathrm{kg}$ for the type $V I$ of interactions in the $a b$ plane is achieved at the angles $\theta=64,117,152,209,242,297$ and $333 \mathrm{deg}$. In the $a c(b c)$ plane, the AO interactions of the type VI can be implemented in the angular regions $339<\theta<21 \mathrm{deg}$ and $159<\theta<181 \mathrm{deg}$ (see Fig. 6c). Finally, accounting for the nonorthogonality of AW polarizations does not affect the AOFM. The AOFM maximum for this type of interactions, $0.1 \times 10^{-15} \mathrm{~s}^{3} / \mathrm{kg}$, is reached at $\theta=21,161,199$ and $339 \mathrm{deg}$ in the $a c(b c)$ plane.

\section{2. $\mathrm{TeO}_{2}$ crystals}

The type $I$ of $\mathrm{AO}$ interactions in $\mathrm{TeO}_{2}$ for the $a c(b c)$ plane is characterized by the highest AOFM value $\left(33.3 \times 10^{-15} \mathrm{~s}^{3} / \mathrm{kg}\right.$ ). Then the AW must propagate along the crystallographic axis $c$ (see Fig. 7a). The maximal deviation of the angular AOFM dependences calculated under alternative conditions when the non-orthogonality effect is accounted for or neglected by is observed at $\theta=38 \mathrm{deg}$. This angle is almost equal to the angle at which the non-orthogonality of the AW QL reaches its highest value (see Fig. 1a). In the $a b$ plane, the maximal AOFM is equal to $9.6 \times 10^{-15} \mathrm{~s}^{3} / \mathrm{kg}$. It is observed at $\theta=0,90,180$ and $270 \mathrm{deg}$ (see Fig. 1b).

At the type $I I$ of interactions, the maximal AOFM value $\left(31.2 \times 10^{-15} \mathrm{~s}^{3} / \mathrm{kg}\right)$ in the $a c(b c)$ plane is achieved at $\theta=64,116,244$ and $296 \mathrm{deg}$ (see Fig. 7b). The AOFM maximum for the $a b$ plane is rather small $\left(0.8 \times 10^{-15} \mathrm{~s}^{3} / \mathrm{kg}\right)$ and is achieved at $\theta=45,135,225$ and $315 \mathrm{deg}$. For the both types $I$ and $I I$ of interactions, consideration of the AW non-orthogonality yields in decreasing AOFM, except for the type $I I$ of interactions in the $a c(b c)$ plane where the non-orthogonality increases the AOFM.
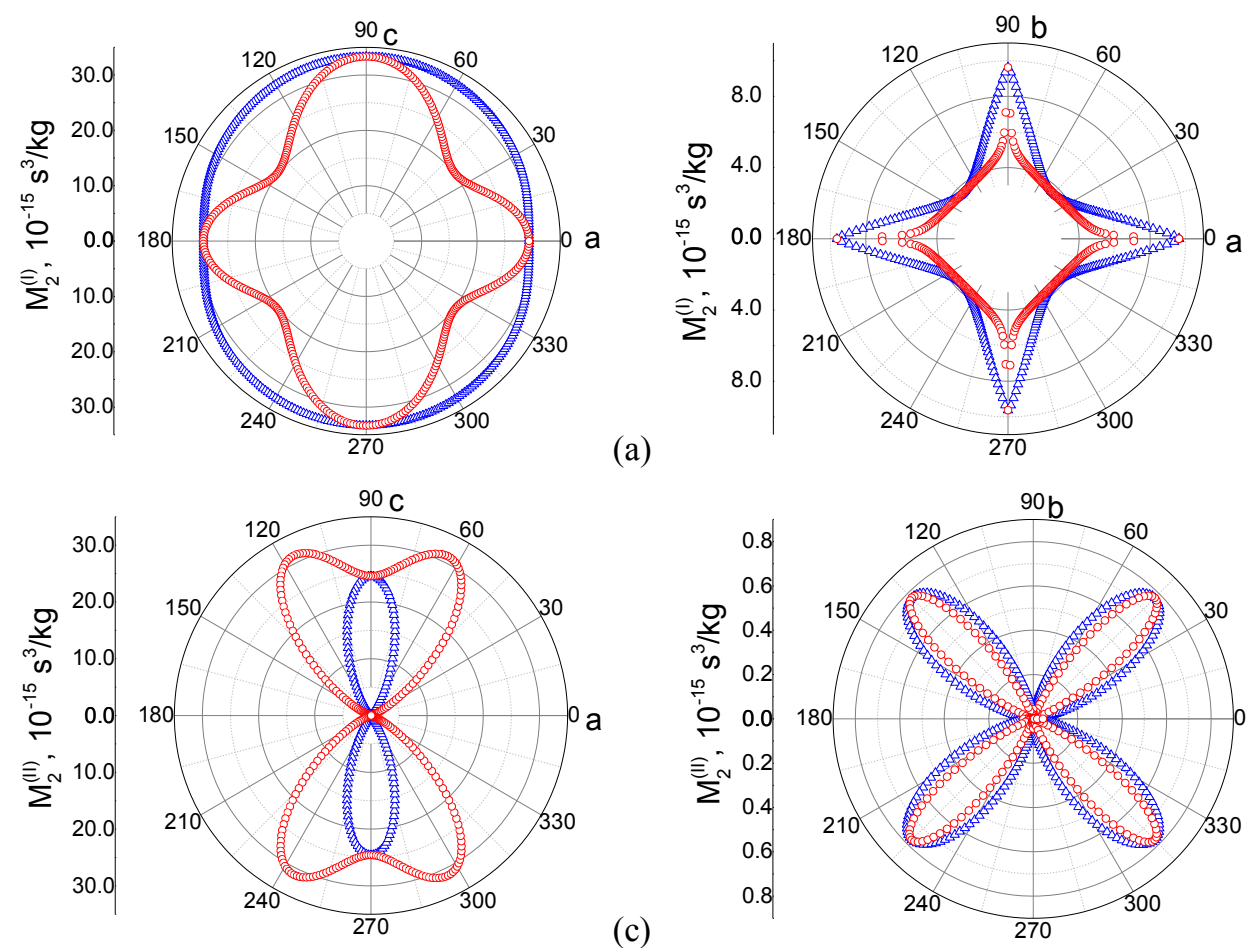

(a)

(c)

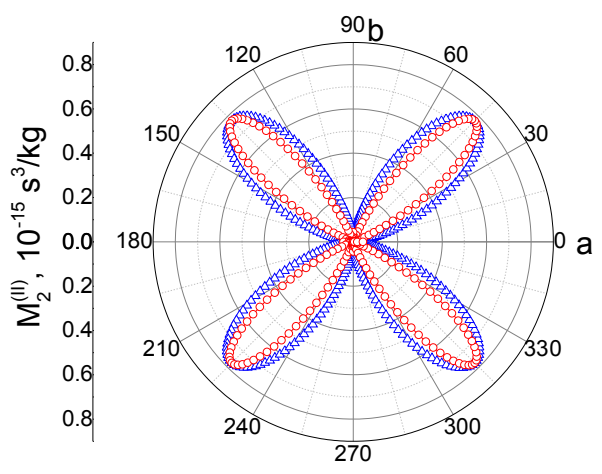

Fig. 7. Dependences of AOFM on the angle $\theta$ for the types $I(a, b)$ and $I I(c, d)$ of AO interactions in the ac $(b c)$ $(a, c)$ and $a b(b, d)$ planes for the $\mathrm{TeO}_{2}$ crystals: open triangles and circles correspond respectively to neglecting and taking the AW non-orthogonality into account. 

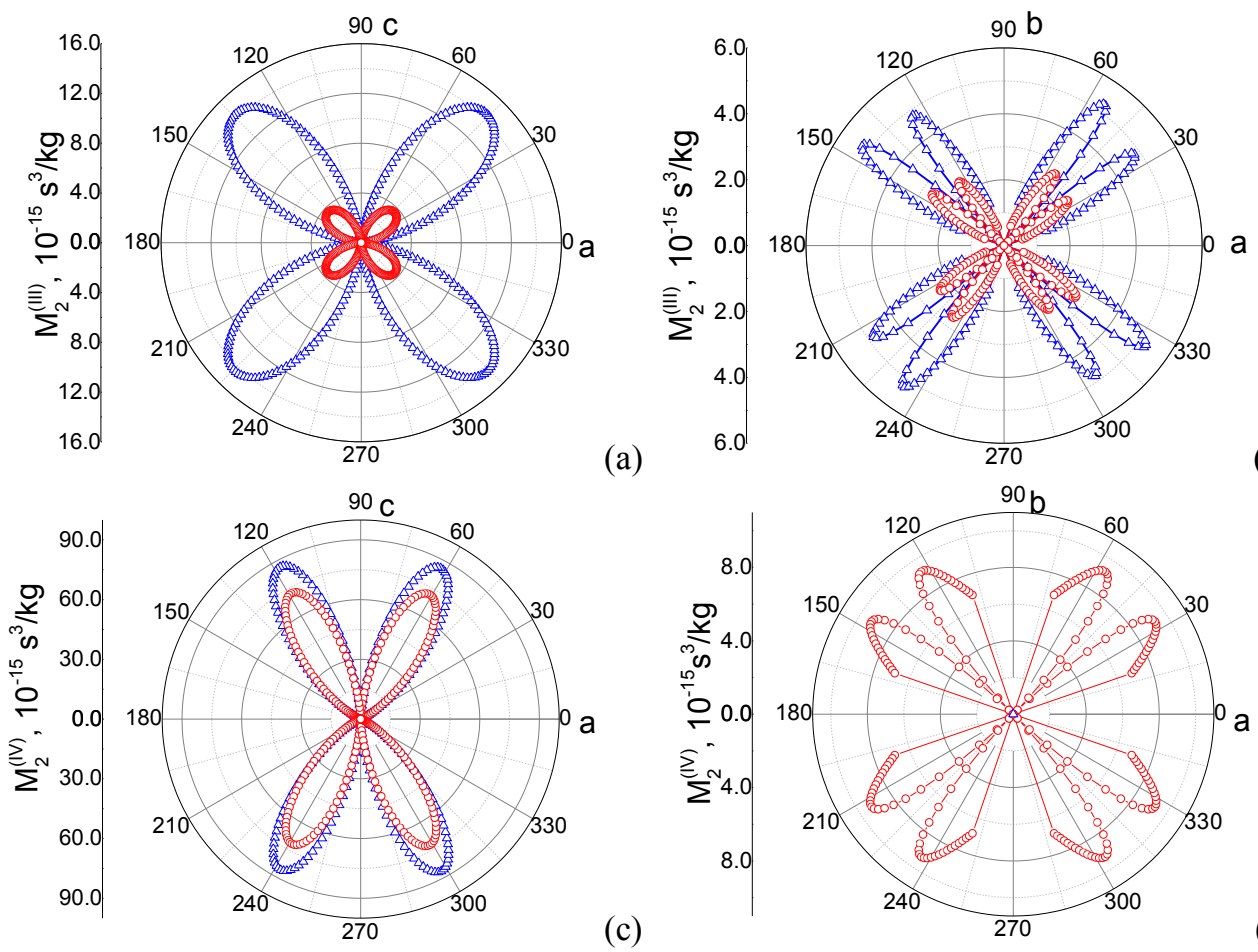

(a)

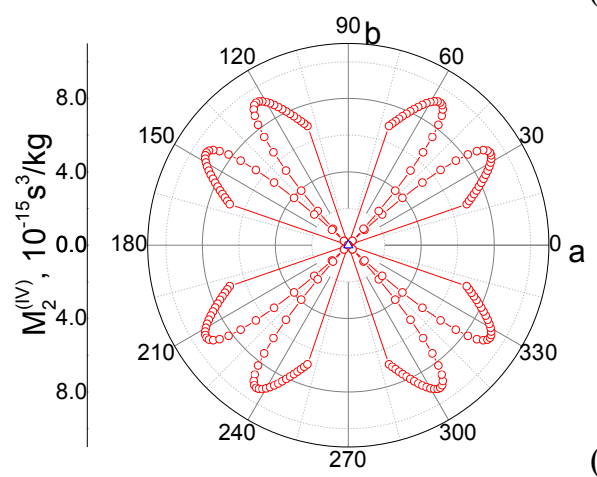

(b)

(c)

Fig. 8. Dependences of AOFM on the angle $\theta$ for the types III (a,b) and $I V(c, d)$ of AO interactions in the ac (bc) $(\mathrm{a}, \mathrm{c})$ and $\mathrm{ab}(\mathrm{b}, \mathrm{d})$ planes for the $\mathrm{TeO}_{2}$ crystals: open triangles and circles correspond respectively to neglecting and taking the AW non-orthogonality into account.

The highest value of AOFM $\left(3.6 \times 10^{-15} \mathrm{~s}^{3} / \mathrm{kg}\right)$ for the interaction type III in the $a c(b c)$ plane is achieved at $\theta=42,138,222$ and $318 \mathrm{deg}$ (see Fig. 8a). Accounting for the non-orthogonality of the AW QT ${ }_{1}$ leads to decreasing AOFM by almost four times. In the $a b$ plane, consideration of the non-orthogonality effect also leads to decreasing AOFM. Here the highest value, $5.3 \times 10^{-15} \mathrm{~s}^{3} / \mathrm{kg}$, can be reached at $\theta=55,145,235$ and $325 \mathrm{deg}$ (see Fig. 8b).

At the type $I V$ of interactions in the $a c(b c)$ plane, the maximal AOFM $\left(71.6 \times 10^{-15} \mathrm{~s}^{3} / \mathrm{kg}\right)$ is reached at $\theta=61,119,241$ and $299 \mathrm{deg}$ (see Fig. 8c). The $V I$ type of interactions for the $a b$ plane is characterized by a much smaller maximal AOFM, $9.3 \times 10^{-15} \mathrm{~s}^{3} / \mathrm{kg}$, which is achieved at $\theta=33$, 57, 123, 147, 213, 237, 303 and $337 \mathrm{deg}$ (see Fig. 8d). Moreover, this interaction type in the

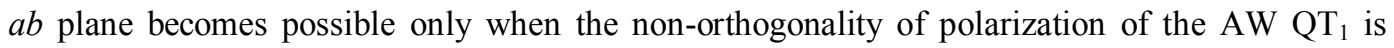
accounted for.
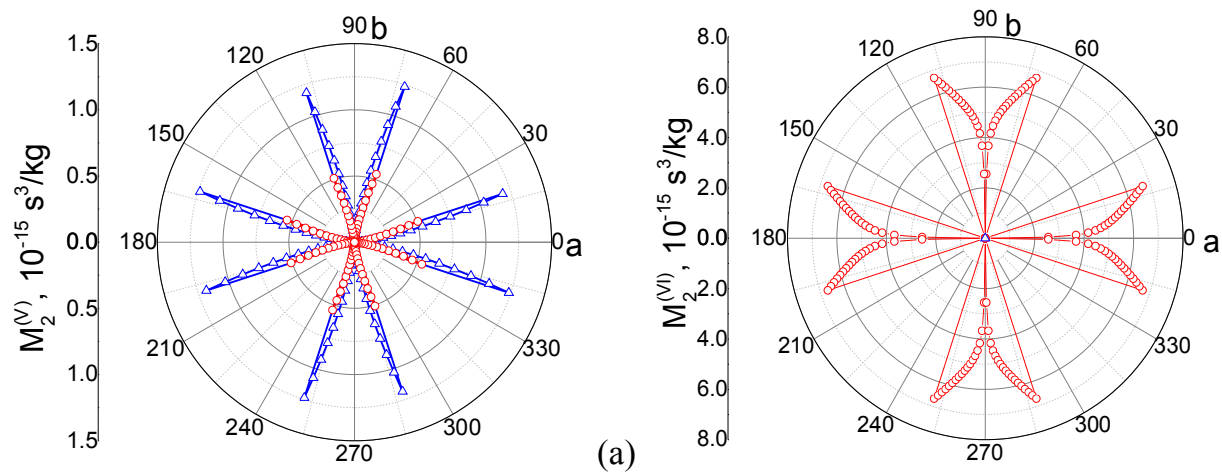

(b)

Fig. 9. Dependences of AOFM on the angle $\theta$ for the types $V(a)$ and $V I$ (b) of $A O$ interactions in the $a b$ plane for the $\mathrm{TeO}_{2}$ crystals: open triangles and circles correspond respectively to neglecting and taking the AW nonorthogonality into account.

Ukr. J. Phys. Opt. 2019, Volume 20, Issue 1 
The types $V$ and $V I$ of AO interactions are impossible in the $a c(b c)$ plane. In the $a b$ plane, the type $V$ of interactions with the $\mathrm{AW} \mathrm{QT}_{2}$ is characterized by the highest AOFM equal to $0.5 \times 10^{-15} \mathrm{~s}^{3} / \mathrm{kg}$. This occurs at $\theta=18,72,108,162,198,252,288$ and $342 \mathrm{deg}$ (see Fig. 9a). At the type $V I$ of interactions, the maximal AOFM, $6.7 \times 10^{-15} \mathrm{~s}^{3} / \mathrm{kg}$, can be observed at the same directions of AW propagation (see Fig. 9b). Notice that, in the latter case, disregarding of the nonorthogonality cancels out the AO interactions in the $a b$ plane.

As seen from Table 1, the global AOFM maximum for the $\mathrm{Li}_{2} \mathrm{~B}_{4} \mathrm{O}_{7}$ crystals is equal to $3.4 \times 10^{-15} \mathrm{~s}^{3} / \mathrm{kg}$ at the isotropic diffraction. This value is achieved at the type $I$ of AO interactions with the $\mathrm{AW} \mathrm{QT}_{1}$ in the crystallographic plane $a c(b c)$. Notice that consideration of the nonorthogonality effect does not changes the type of AO interactions at which the AOFM maximum is achieved. Moreover, this does not change the value of the maximum itself. Namely, under the conditions of neglect by the non-orthogonality, the maximal AOFM value $3.4 \times 10^{-15} \mathrm{~s}^{3} / \mathrm{kg}$ has been detected in our recent work [9] in the case of the type $I$ of AO interactions. Finally, the global AOFM maximum for the isotropic AO interactions in $\mathrm{TeO}_{2}, 71.0 \times 10^{-15} \mathrm{~s}^{3} / \mathrm{kg}$, is reached at the type $I V$ of $\mathrm{AO}$ interactions in the $a c(b c)$ interaction plane.

Table 1. Maximal AOFM values calculated for the $\mathrm{Li}_{2} \mathrm{~B}_{4} \mathrm{O}_{7}$ and $\mathrm{TeO}_{2}$ crystals at different types of isotropic AO interactions.

\begin{tabular}{|c|c|c|c|c|c|c|}
\hline $\begin{array}{l}\text { Type of AO } \\
\text { interactions }\end{array}$ & $I$ & II & III & $I V$ & $\bar{V}$ & $V I$ \\
\hline \multicolumn{7}{|c|}{$\mathrm{Li}_{2} \mathrm{~B}_{4} \mathrm{O}_{7}$} \\
\hline $\begin{array}{l}\text { Angle } \theta \text {, } \\
\text { deg }\end{array}$ & 90,270 & $\begin{array}{l}45,135 \\
225,315\end{array}$ & 90,270 & 90,270 & $\begin{array}{c}64,152 \\
242,333\end{array}$ & $\begin{array}{l}21,161, \\
199,339\end{array}$ \\
\hline $\begin{array}{l}\text { Interaction } \\
\text { plane }\end{array}$ & $a c(b c)$ & $a b$ & $a c(b c)$ & $a c(b c)$ & $a b$ & $a c(b c)$ \\
\hline $\begin{array}{l}\text { AOFM, } \\
10^{-15} \mathrm{~s}^{3} / \mathrm{kg}\end{array}$ & 3.4 & 1.7 & 0.8 & 0.4 & 0.006 & 0.1 \\
\hline \multicolumn{7}{|c|}{$\mathrm{TeO}_{2}$} \\
\hline $\begin{array}{l}\text { Angle } \theta, \\
\text { deg }\end{array}$ & 90 & $\begin{array}{l}64,116, \\
244,296\end{array}$ & $\begin{array}{c}55,145 \\
235,325\end{array}$ & $\begin{array}{l}61,119, \\
241,299\end{array}$ & $\begin{array}{c}18,72,108, \\
162,198,252, \\
288,342\end{array}$ & $\begin{array}{c}18,72,108, \\
162,198,252, \\
288,342\end{array}$ \\
\hline $\begin{array}{l}\text { Interaction } \\
\text { plane }\end{array}$ & $a c(b c)$ & $a c(b c)$ & $a b$ & $a c(b c)$ & $a b$ & $a b$ \\
\hline $\begin{array}{l}\text { AOFM, } \\
10^{-15} \mathrm{~s}^{3} / \mathrm{kg}\end{array}$ & 33.3 & 31.2 & 5.3 & 71.6 & 0.5 & 6.7 \\
\hline
\end{tabular}

\section{Conclusions}

In the present work we have analyzed the AOFM anisotropy at the isotropic AO diffraction in $\mathrm{Li}_{2} \mathrm{~B}_{4} \mathrm{O}_{7}$ and $\mathrm{TeO}_{2}$. We have restricted ourselves to experimental geometries in the crystallographic planes but taken into account the effect of non-orthogonality of AW polarizations.

The geometries of AO diffraction at which the maximal AOFM values have to be observed are obtained for all of the six types of isotropic AO interactions. We have found that the global AOFM maximum for the $\mathrm{Li}_{2} \mathrm{~B}_{4} \mathrm{O}_{7}$ crystals and the isotropic diffraction is equal to $3.4 \times 10^{-15} \mathrm{~s}^{3} / \mathrm{kg}$. This value is achieved at the type $I$ of AO interactions with the $\mathrm{AW} \mathrm{QT}_{1}$ in the crystallographic plane $a c(b c)$. Accounting for the non-orthogonality effect changes neither the type of AO interactions at which the AOFM maximum is achieved nor the value of this maximum. The AOFM maximum for the $\mathrm{TeO}_{2}$ crystals under condition of isotropic diffraction $\left(71.0 \times 10^{-15} \mathrm{~s}^{3} / \mathrm{kg}\right)$ is reached at the type $I V$ of $\mathrm{AO}$ interactions in the interaction plane $a c(b c)$. 
Finally, we have corrected the formulae for the EEC, which have to be used when calculating the AOFM for the KDP and ADP crystals. The corresponding corrections have also been made in the expressions for the maximal AOFM values.

\section{Appendix}

The formulae for the EEC published in our recent work [1] contain the errors that concern the factors 2 or 0.5 . In the relations presented below, the corrections of these formulas are indicated in bold font.

For the type $I$ of AO interactions of the quasi-ordinary optical wave with the quasilongitudinal AW in the crystallographic plane $a c(b c)$, the EEC without accounting for the deviation of AW polarization from the purely longitudinal state is given by

$$
p_{e f}^{(I)}=p_{12} \cos ^{2} \theta+p_{13} \sin ^{2} \theta .
$$

The same relation written with accounting for the angle of deviation from the purely longitudinal AW acquires the form

$$
\begin{aligned}
p_{e f}^{(I)}= & p_{12}\left(\cos ^{2} \theta \cos (\theta-\zeta)-\sin 2 \theta \sin (\theta-\zeta)\right) \\
& +p_{13}\left(\sin ^{2} \theta \cos (\theta-\zeta)+\sin 2 \theta \sin (\theta-\zeta)\right)
\end{aligned} .
$$

If we disregard or take into account the angle of deviation of the AW polarization from the purely longitudinal state, the EEC for the $a b$ plane can be written respectively as

$$
\begin{gathered}
p_{e f}^{(I)}=\cos ^{2}\left(\theta+\theta_{B}\right)\left(p_{11} \cos ^{2} \theta+p_{12} \sin ^{2} \theta\right) \\
+\sin ^{2}\left(\theta+\theta_{B}\right)\left(p_{12} \cos ^{2} \theta+p_{11} \sin ^{2} \theta\right), \\
+p_{66} \sin 2\left(\theta+\theta_{B}\right) \sin 2 \theta \\
p_{e f}^{(I)}=\cos ^{2}\left(\theta+\theta_{B}\right)\left\{\begin{array}{l}
\left(p_{11}\left(\cos ^{2} \theta \cos (\theta-\zeta)-\sin 2 \theta \sin (\theta-\zeta)\right)\right. \\
+p_{12}\left(\sin ^{2} \theta \cos (\theta-\zeta)+\sin 2 \theta \sin (\theta-\zeta)\right)
\end{array}\right\} \\
+\sin ^{2}\left(\theta+\theta_{B}\right)\left\{\begin{array}{l}
p_{12}\left(\cos ^{2} \theta \cos (\theta-\zeta)-\sin 2 \theta \sin (\theta-\zeta)\right) \\
+p_{11}\left(\sin ^{2} \theta \cos (\theta-\zeta)+\sin 2 \theta \sin (\theta-\zeta)\right)
\end{array}\right\} . \\
+2 p_{66} \sin 2\left(\theta+\theta_{B}\right)(\cos 2 \theta \sin (\theta-\zeta)+0.5 \sin 2 \theta \cos (\theta-\zeta))
\end{gathered}
$$

For the type $I I$ of isotropic AO interactions of the quasi-extraordinary optical wave with the quasi-longitudinal $\mathrm{AW}$ in the $a c(b c)$ plane, one can write the EEC

$$
\begin{aligned}
p_{e f}^{(I I)} & =\cos ^{2}\left(\theta+\theta_{B}\right)\left(p_{11} \cos ^{2} \theta+p_{13} \sin ^{2} \theta\right) \\
& +\sin ^{2}\left(\theta+\theta_{B}\right)\left(p_{31} \cos ^{2} \theta+p_{33} \sin ^{2} \theta\right), \\
& +p_{44} \sin 2\left(\theta+\theta_{B}\right) \sin 2 \theta
\end{aligned}
$$

when the deviation of AW polarization from the purely longitudinal state is neglected. The same parameter with accounting for the above deviation becomes as follows:

$$
\begin{aligned}
p_{e f}^{(I I)}= & \cos ^{2}\left(\theta+\theta_{B}\right)\left\{\begin{array}{l}
p_{11}\left(\cos ^{2} \theta \cos (\theta-\zeta)-\sin 2 \theta \sin (\theta-\zeta)\right) \\
+p_{13}\left(\sin ^{2} \theta \cos (\theta-\zeta)+\sin 2 \theta \sin (\theta-\zeta)\right)
\end{array}\right\} \\
& +\sin ^{2}\left(\theta+\theta_{B}\right)\left\{\begin{array}{l}
p_{31}\left(\cos ^{2} \theta \cos (\theta-\zeta)-\sin 2 \theta \sin (\theta-\zeta)\right) \\
+p_{33}\left(\sin ^{2} \theta \cos (\theta-\zeta)+\sin 2 \theta \sin (\theta-\zeta)\right)
\end{array}\right\} . \\
& +2 p_{44} \sin 2\left(\theta+\theta_{B}\right)(\cos 2 \theta \sin (\theta-\zeta)+0.5 \sin 2 \theta \cos (\theta-\zeta))
\end{aligned}
$$

The same relations for the type $I I$ of isotropic AO interactions of the quasi-extraordinary optical wave with the quasi-longitudinal AW in the $a b$ plane are as follows: 


$$
\begin{aligned}
& p_{e f}^{(I I)}=p_{31}, \\
& p_{e f}^{(I I)}=p_{31} \cos (\theta-\zeta) .
\end{aligned}
$$

The EEC for the type $I I I$ of $\mathrm{AO}$ interactions in the $a c(b c)$ plane is defined by the relations

$$
\begin{aligned}
p_{e f}^{(I I I)} & =\boldsymbol{0 . 5}\left(p_{12}-p_{13}\right) \sin 2 \theta, \\
p_{e f}^{(I I I)} & =\mathbf{0 . 5} p_{12}\left(\cos ^{2} \theta \cos (\zeta-\theta)-\sin 2 \theta \sin (\zeta-\theta)\right), \\
& +\boldsymbol{0} .5 p_{13}\left(\sin ^{2} \theta \cos (\zeta-\theta)+\sin 2 \theta \sin (\zeta-\theta)\right),
\end{aligned}
$$

which are derived respectively under conditions of neglecting by and accounting for the angle of AW non-orthogonality.

For the type $I V$ of AO interactions of the incident quasi-extraordinary optical wave with the $\mathrm{AW}_{1}$ in the $a c(b c)$ plane we obtain the EEC

$$
\begin{aligned}
& p_{e f}^{(I V)}=0.5 \cos ^{2}\left(\theta+\theta_{B}\right)\left(p_{11}-p_{13}\right) \sin 2 \theta \\
& +0.5 \sin ^{2}\left(\theta+\theta_{B}\right)\left(p_{31}-p_{33}\right) \sin 2 \theta \text {, } \\
& -p_{44} \sin 2\left(\theta+\theta_{B}\right) \cos 2 \theta \\
& p_{e f}^{(I V)}=0.5 \cos ^{2}\left(\theta+\theta_{B}\right)\left\{\begin{array}{l}
p_{11}\left(\cos ^{2} \theta \cos (\zeta-\theta)-\sin 2 \theta \sin (\zeta-\theta)\right) \\
+p_{13}\left(\sin ^{2} \theta \cos (\zeta-\theta)+\sin 2 \theta \sin (\zeta-\theta)\right)
\end{array}\right\} \\
& +0.5 \sin ^{2}\left(\theta+\theta_{B}\right)\left\{\begin{array}{l}
p_{31}\left(\cos ^{2} \theta \cos (\zeta-\theta)-\sin 2 \theta \sin (\zeta-\theta)\right) \\
+p_{33}\left(\sin ^{2} \theta \cos (\zeta-\theta)+\sin 2 \theta \sin (\zeta-\theta)\right)
\end{array}\right\}, \\
& -p_{44} \sin 2\left(\theta+\theta_{B}\right)(0.5 \sin 2 \theta \cos (\zeta-\theta)+\cos 2 \theta \sin (\zeta-\theta))
\end{aligned}
$$

for the alternative cases when the non-orthogonality effect is disregarded or taken into account.

For the interaction plane $a b$, the types $I I I$ and $I V$ of AO interactions cannot be implemented with the $\mathrm{AW} \mathrm{QT}_{1}$, since the corresponding elasto-optic coefficients are equal to zero. The same is true for the interaction plane $a c$ in case of the types $V$ and $V I$ of $\mathrm{AO}$ interactions.

For the $a b$ plane, the EEC at the type $V$ of interactions for the angles in the first quadrant ( $0 \mathrm{deg}<\theta<V_{1}$ and $V_{2}<\theta<90 \mathrm{deg}$ ) can be written as

$$
p_{e f}^{(V)}=\mathbf{0 . 5}\left(p_{11}-p_{12}\right) \sin 2 \theta \cos 2\left(\theta+\theta_{B}\right)-p_{66} \sin 2\left(\theta+\theta_{B}\right) \cos 2 \theta,
$$

when the non-orthogonality of AWs is not accounted for. In the alternative case of proper consideration of the effect we arrive at the relation

$$
\begin{aligned}
p_{e f}^{(V)}= & 0.5 \cos ^{2}\left(\theta+\theta_{B}\right)\left\{\begin{array}{l}
p_{11}\left(\cos ^{2} \theta \cos (\zeta-\theta)-\sin 2 \theta \sin (\zeta-\theta)\right) \\
+p_{12}\left(\sin ^{2} \theta \cos (\zeta-\theta)+\sin 2 \theta \sin (\zeta-\theta)\right)
\end{array}\right\} \\
& +0.5 \sin ^{2}\left(\theta+\theta_{B}\right)\left\{\begin{array}{l}
p_{12}\left(\cos ^{2} \theta \cos (\zeta-\theta)-\sin 2 \theta \sin (\zeta-\theta)\right) \\
+p_{11}\left(\sin ^{2} \theta \cos (\zeta-\theta)+\sin 2 \theta \sin (\zeta-\theta)\right)
\end{array}\right\} . \\
& -p_{66} \sin 2\left(\theta+\theta_{B}\right)(0.5 \sin 2 \theta \cos (\zeta-\theta)+\cos 2 \theta \sin (\zeta-\theta))
\end{aligned}
$$

The EEC for the type $V I$ of AO interaction in the $a b$ plane and the angles of incidence of the optical wave in the first quadrant $0 \mathrm{deg}<\theta<V_{1}$ and $V_{2}<\theta<90 \mathrm{deg}$ can be represented as

$$
p_{e f}^{(V I)}=\boldsymbol{0 . 5}\left(p_{31}-p_{32}\right) \sin 2 \theta=0 \text { for tetragonal crystals, since } p_{32}=p_{31} \text {. }
$$

This formula concerns a hypothetic case of orthogonal AWs. The alternative is given by the formula 


$$
p_{e f}^{(V I)}=p_{31} \cos (\zeta-\theta) .
$$

The above corrections for the EEC impose some changes in the geometries and types of AO interactions at which the maximal AOFM values are achieved in the KDP and ADP crystals (see Table 1A). So, the largest AOFM maximum among the figures typical for the KDP crystals is equal to $3.2 \times 10^{-15} \mathrm{~s}^{3} / \mathrm{kg}$ in case of the isotropic diffraction. It is peculiar for the type $I$ of AO interactions. The same value for the ADP crystals is equal to $6.9 \times 10^{-15} \mathrm{~s}^{3} / \mathrm{kg}$. It is typical for the type III of AO interactions.

Table 1A. Maximal AOFM values for the ADP and KDP crystals, which are observed at different types of isotropic AO interactions.

\begin{tabular}{|c|c|c|c|c|c|c|}
\hline $\begin{array}{l}\text { Type of AO } \\
\text { interaction }\end{array}$ & $I$ & $I I$ & III & $I V$ & $V$ & $V I$ \\
\hline \multicolumn{7}{|c|}{ KDP } \\
\hline $\begin{array}{l}\text { Angle } \theta, \\
\text { deg }\end{array}$ & $\begin{array}{l}45,135 \\
225,315\end{array}$ & $\begin{array}{l}45,135 \\
225,315\end{array}$ & $\begin{array}{c}41,49,131, \\
139,221, \\
229,311,319\end{array}$ & $\begin{array}{c}25,65, \\
115,155, \\
205,245, \\
295,335\end{array}$ & 71,341 & $\begin{array}{c}18,71,108, \\
162,198, \\
252,288,341\end{array}$ \\
\hline $\begin{array}{l}\text { Interaction } \\
\text { plane }\end{array}$ & $a b$ & $a b$ & $a b$ & $a b$ & $a b$ & $a b$ \\
\hline $\begin{array}{l}\text { AOFM, } \\
10^{-15} \mathrm{~s}^{3} / \mathrm{kg} \\
\end{array}$ & 3.2 & 2.2 & 0.2 & 0.4 & 0.001 & 0.4 \\
\hline \multicolumn{7}{|c|}{ ADP } \\
\hline $\begin{array}{l}\text { Angle } \theta \text {, } \\
\text { deg }\end{array}$ & $\begin{array}{l}45,135 \\
225,315\end{array}$ & $\begin{array}{l}45,135 \\
225,315\end{array}$ & $\begin{array}{c}23,67,113, \\
157,203, \\
247,293,337\end{array}$ & $\begin{array}{c}27,63, \\
117,153, \\
207,243, \\
297,333\end{array}$ & $\begin{array}{c}13,77,103, \\
166,193, \\
257,283, \\
346\end{array}$ & $\begin{array}{c}13,77,103, \\
166,193, \\
257,283,346\end{array}$ \\
\hline $\begin{array}{l}\text { Interaction } \\
\text { plane }\end{array}$ & $a b$ & $a c(b c)$ & $a b$ & $a b$ & $a b$ & $a b$ \\
\hline $\begin{array}{l}\text { AOFM, } \\
10^{-15} \mathrm{~s}^{3} / \mathrm{kg}\end{array}$ & 3.6 & 3.6 & 6.9 & 1.5 & 5.3 & 1.0 \\
\hline
\end{tabular}

Acknowledgement. The authors acknowledge financial support of the present study from the Ministry of Education and Science of Ukraine under the projects \# 0117U000802 and 0118 U003999.

\section{References}

1. Mys O, Kostyrko M, Adamenko D and Vlokh R, 2018. Anisotropy of acousto-optic figure of merit in tetragonal crystals with accounting for non-orthogonality of acoustic eigenwave polarizations. 1. The cases of $\mathrm{KH}_{2} \mathrm{PO}_{4}$ and $\mathrm{NH}_{4} \mathrm{H}_{2} \mathrm{PO}_{4}$ crystals. Ukr. J. Phys. Opt. 19: 220236.

2. Shaskolskaya M P. Acoustic crystals. Moscow: Nauka (1982).

3. Yano $\mathrm{T}$ and Watanabe A, 1974. Acoustooptic figure of merit of $\mathrm{TeO}_{2}$ for circularly polarized light. J. Appl. Phys. 45: 1243-1245.

4. Vlokh R, Dyachok Ya, Krupych O, Burak Ya, Martunyuk-Lototska I, Andrushchak A and Adamiv V, 2003. Study of laser-induced damage of borate crystals. Ukr. J. Phys. Opt. 4: 101104.

5. Komatsu R, Sugawara T, Sassa K, Sarukura N, Liu Z, Izumida S, Segawa Y, Uda S, Fukuda T and Yamanouchi K, 1997. Growth and ultraviolet application of $\mathrm{Li}_{2} \mathrm{~B}_{4} \mathrm{O}_{7}$ crystals: generation of the fourth and fifth harmonics of $\mathrm{Nd}: \mathrm{Y}_{3} \mathrm{Al}_{5} \mathrm{O}_{12}$ lasers. Appl. Phys. Lett. 70: 3492-3494. 
6. Martynyuk-Lototska I, Mys O, Dudok T, Adamiv V, Smirnov Y and Vlokh R, 2008. Acoustooptic interaction in $\alpha-\mathrm{BaB}_{2} \mathrm{O}_{4}$ and $\mathrm{Li}_{2} \mathrm{~B}_{4} \mathrm{O}_{7}$ crystals. Appl. Opt. 47: 3446-3454.

7. Martynyuk-Lototska I, Mys O, Krupych O, Adamiv V, Burak Ya, Vlokh R and Schranz W, 2004. Elastic, piezooptic and acoustooptic properties of borate crystals $\left(\mathrm{BaB}_{2} \mathrm{O}_{4}, \mathrm{Li}_{2} \mathrm{~B}_{4} \mathrm{O}_{7}\right.$ and $\mathrm{CsLiB}_{6} \mathrm{O}_{10}$ ). Integrated Ferroelectrics. 63: 99-103.

8. Krupych O, Mys O, Kryvyy T, Adamiv V, Burak Y and Vlokh R, 2016. Photoelastic properties of lithium tetraborate crystals. Appl. Opt. 55: 10457-10462.

9. Mys O, Krupych O and Vlokh R, 2018. Anisotropy of acousto-optic figure of merit in lithium tetraborate crystals. J. Mod. Opt. 65: 1486-1494.

10. Mys O, Kostyrko M, Smyk M, Krupych O and Vlokh R, 2014. Anisotropy of acoustooptic figure of merit for $\mathrm{TeO}_{2}$ crystals. 1. Isotropic diffraction. Ukr. J. Phys. Opt. 15: 132-154.

11. Mys O., Kostyrko M., Zapeka B., Krupych O. and Vlokh R. 2016. Anisotropy of acoustooptic figure of merit for $\mathrm{TeO}_{2}$ crystals. 2. Anisotropic diffraction: Errata. Ukr. J. Phys. Opt. 17: $148-166$.

12. Mys O, Adamenko D, Krupych O and Vlokh R, 2018. Effect of deviation from purely transverse and longitudinal polarization states of acoustic waves on the anisotropy of acoustooptic figure of merit: The case of $\mathrm{Tl}_{3} \mathrm{AsS}_{4}$ crystals. Appl. Opt. 57: 8320-8330.

13. Bohaty L, Haussühl S and Liebertz J, 1989. Electrooptical coefficients and temperature and pressure derivatives of the elastic constants of tetragonal $\mathrm{Li}_{2} \mathrm{~B}_{4} \mathrm{O}_{7}$. Cryst. Res. Technol. 24: 1159-1163.

14. Uchida N, 1971. Optical properties of single-crystals paratellurite $\left(\mathrm{TeO}_{2}\right)$. Phys. Rev. B. 4: 3736-3745.

15. Shiosaki T, Adachi M, Kobayashi H, Araki K and Kawabata A, 1985. Elastic, piezoelectric, acousto-optic and electro-optic properties of $\mathrm{Li}_{2} \mathrm{~B}_{4} \mathrm{O}_{7}$. Japan. J. Appl. Phys. 24: 25-27.

16. Uchida $\mathrm{N}$ and Ohmachi Y, 1969. Elastic and photoelastic properties of $\mathrm{TeO}_{2}$ single crystal. J. Appl. Phys. 40: 4692-4695.

17. Krupych O, Mys O, Kryvyy T, Adamiv V, Burak Y and Vlokh R, 2016. Photoelastic properties of lithium tetraborate crystals. Appl. Opt. 55: 10457-10462.

18. Balakshyi V I, Paryhyn V N and Chyrkov L E. Physical foundations of acoustooptics. Moscow: Radio and Communications (1985).

Mys O., Savaryn V., Kostyrko M., Adamenko D., Krupych O. and Vlokh R. 2019. Anisotropy of acousto-optic figure of merit in tetragonal crystals with accounting for non-orthogonality of acoustic eigenwave polarizations. 2. The cases of $\mathrm{Li}_{2} \mathrm{~B}_{4} \mathrm{O}_{7}$ and $\mathrm{TeO}_{2}$ crystals. Ukr.J.Phys.Opt. 20: 23 - 36. doi: 10.3116/16091833/20/1/23/2019

Анотація. Проаналізовано анізотропію акустооптичного параметра якості (АОПЯ) $M_{2}$ для ізотропної акустооптичної (AO) дифракиї в кристалах $\mathrm{Li}_{2} \mathrm{~B}_{4} \mathrm{O}_{7}$ i ТеО $\mathrm{Te}_{2}$. Розглянуто дифракцію в межах кристалографічних площчин за умови врахування ефекту неортогональності поляризачій акустичних хвиль. Для всіх типів ізотропних АО-взаємодій визначено ті геометрії дифракиії, для яких досягаємо максимальних значень АОФМ. Встановлено, щчо глобальний максимум АОПЯ для $\mathrm{Li}_{2} \mathrm{~B}_{4} \mathrm{O}_{7}$ y разі ізотропної дифракиї дорівнює $M_{2}=3.4 \times 10^{-15} \mathrm{c}^{3} / \kappa 2$. Він має місие для типу I AO-взаємодій із акустичною хвилею $Q T_{1}$ у кристалографічних площчинах ас або bс. Для кристалів ТеО ${ }_{2}$ максимум АОПЯ для ізотропних АО-взаємодій $\left(M_{2}=71,0 \times 10^{-15} c^{3} / к 2\right)$ досягаємо для типу IV AO-взаємодій $y$ головних площчнах ас або $b c$. 